\section{A coleção "povos indígenas do oiapoque - mae": composição e contexto de formação ${ }^{1}$}

\author{
Esther De Castro ${ }^{2}$
}

Este artigo tem por objetivo propor uma reflexão sobre a formação das coleções etnográficas. A coleta de cultura material é uma prática que tem variado de acordo com as mudanças no foco de interesses e propostas teóricas da Antropologia. As coleções, como resultantes diretas dessa prática, apresentam características que as remetem aos seus contextos de formação. Refletir sobre esse tema implica em considerar as coleções etnográficas como construções sociais; proposta que encontra um respaldo teórico importante na renovação dos estudos de coleções, conforme Pearce ( 1999 ) entre outros.

Este estudo aborda a relação entre a composição - quantidade e categoria de objetos - de uma coleção etnográfica e o seu contexto de formação. Refere-se ao acervo de cultura material coletado entre os grupos indígenas Karipuna, Galibi Marworno e Palikur durante a década de 1990 e atualmente guardado no Museu de Arqueologia e Etnologia ( MAE ) da Universidade de São Paulo ( USP ). Trata-se de um conjunto de cerca de 260 objetos coletados em grande parte pela antropóloga Lux Boelitz Vidal e, em menor proporção, pela, na época sua aluna mestranda do Departamento de Antropologia da USP, Artionka Capiberibe. A formação dessa coleção, que passo a denominar de "Coleção Povos Indígenas do Oiapoque no MAE " insere-se em um contexto de relações pontuais entre os grupos indígenas acima citados e os seus pesquisadores.

\section{Os Povos Indígenas do Oiapoque}

Os grupos indígenas Karipuna, Galibi Marworno e Palikur, juntamente com os Gali-

1 Trabalho apresentado na Mesa 2: Acervos etnológicos e curadoria científica.

2 Mestre em Antropologia. Professora no Centro Universitário FIEO. bi Kalinã habitam o extremo norte no Brasil, estado do Amapá, município de Oiapoque, nas reserva indígenas Uaçá, Galibi e Juminã. Com uma população de cerca de 5.000 pessoas, estão distribuídos em mais de 20 aldeias, localizadas preferencialmente ao longo dos grandes rios Oiapoque, Uaçá, Curipi e Urukawá.

Os Karipuna concentram-se no rio Curipi, com aldeias menores ao longo da $\mathrm{Br}-156$, no rio Oiapoque e no igarapé Juminã. Falam a língua patoa e o português. Formaram-se a partir de remanescentes de várias populações indígenas da região e de famílias do Salgado Paraense.

Os Galibi Marworno localizam-se no rio Uaçá e em uma pequena aldeia ao longo da $\mathrm{Br}-156$. No século XVIII vivenciaram experiências de dispersão com as missões jesuíticas, no século XIX as explorações dos comerciantes e no século XX, a política do SPI Serviço de Proteção ao Índios reuniu os diversos aldeamentos em um só: a atual aldeia de Kumarumã. Falam as línguas patoa e português; das línguas faladas pelos grupos indígenas que os formaram, principalmente os Maraone e os Aruã, possuem a memória de algumas poucas palavras.

Os Palikur localizam-se, em sua maioria, no rio Urukawá, mas também na Guiana Francesa - ao longo do rio Oiapoque, em Saint George e em Caiena. São os mais antigos na região e desde o século XVI são mencionadas suas relações comerciais com os franceses. Recusaram a presença de missionários e a implantação da escola, que passou a funcionar apenas na década de 60 , quando iniciou-se também a conversão deles ao pentecostalismo. No entanto, eles possuem uma memória bastante detalhada de seus mitos, visões cosmológicas e de alguns importantes itens de cultura material. Falam a língua Pa'ikwaki e usam o patoa, o português e o francês para situações fora das aldeias.

Os Galibi Kalinã localizam-se no rio Oiapoque. Desde o século XVII são mencionados em relatos de viajantes; no século XVIII fo- 
ram aldeados em missões jesuíticas e retomaram as aldeias no século XIX; em 1950, imigraram para o Brasil, provenientes da aldeia de Maná, na Guiana Francesa. Falam a língua Galibi, o patoá, o francês e o português.

A identidade Povos Indígenas do Oiapoque insere-se em um processo recente. No início do século XX, há a resolução do Contestado franco brasileiro, em que o Amapá passou a pertencer ao Brasil, o que significou maior vigilância nas fronteiras para garanti-las. Nos anos 30 e 40, intensificou-se a necessidade da presença política nacional nas fronteiras e, por isso, os povos que alí habitavam passaram para o controle do SPI com o propósito de "nacionaliza-los", " civilizalos”, declarando-os índios brasileiros. Na década de 70, inicia-se a atuação do CIMI - Conselho Indigenista Missionário - com diretrizes visando a valorização e autonomia dos grupos indígenas. Destacam-se o movimento das cooperativas, a realização de Assembléias, os projetos de educação diferenciada e o processo de demarcação das reservas indígenas. A década de 80 é marcada por debates por autonomia e cidadania e em 1992 é homologado o território indígena e fundada a Associação dos Povos Indígenas do Oiapoque.

Nesse contexto, no início dos anos 90 , iniciaram-se as pesquisas antropológicas com os grupos indígenas da área, coordenadas por Lux B. Vidal. Um longo processo que tem, como uma das resultantes, a formação da coleção depositada no MAE.

\section{A coleção "Povos Indígenas do Oiapoque - MAE"}

O que pretendo enfatizar é que a coleção "Povos indígenas do Oiapoque - MAE " não é resultante de critérios de seleção de objetos, fixados à priori com o objetivo de escolher e recolher determinados exemplares de cultura material considerados representativos desses povos indígenas, conforme procedimentos clássicos do trabalho de campo. Ao contrário, sem implicar em uma rígida seleção dos objetos, os critérios para a composição dessa coleção foram dados pela postura teórica e pelo exercício do fazer antropologia da principal coletora, Lux Vidal. Trata-se de um conjunto de objetos, que foi se materializando como parte de um processo de reflexão e trabalho desenvolvido com a participação da coletora, de alunos, colaboradores e índios.

Uma coleção é uma construção cultural, e, nesse sentido, podemos aborda-la, evidenciando as relações entre as categorias e quantidades de objetos presentes na coleção e o seu contexto de formação. $\mathrm{O}$ trabalho da principal coletora Lux Vidal apresenta características que se relacionam com a constituição da coleção, dentre as quais destacamos o viés teórico assumido pela antropóloga para a pesquisa na área, o seu trabalho de orientadora junto ao programa de pós-graduação em Antropologia Social do Departamento de Antropologia da USP e a sua atuação como coordenadora de projetos de assessoria aos Povos Indígenas do Oiapoque.

\section{A Postura Teórica da Coletora e a Composição da Coleção}

Destacamos o exercício da crítica a certos conceitos antropológicos como fundamental para o entendimento das categorias de objetos coletados. Como membro do Núcleo de História Indígena e do Indigenismo da Universidade de São Paulo e coordenadora , juntamente com Dominique T. Gallois, do Grupo Temático "As Sociedades Indígenas e suas Fronteiras na Região Sudeste das Guianas", Lux Vidal vai desenvolver junto a esse grupo uma postura crítica em relação a conceitos fundamentais para o entendimento adequado dos povos indígenas em questão.

Trata-se de povos indígenas com intenso contato interétnico, cuja configuração geopolítica atual tem suas raízes no modo como cada um deles vivenciou a ocupação colonial na região amazônica. Especialmente para a região do Oiapoque a história de contatos interétnicos, migrações e agrupamentos 
é registrada em relatos de viajantes e em documentos desde o início da colonização no século XVI.

Essas sociedades eram vistas como atomizadas, fechadas em si próprias e o contato era visto, evidentemente, como uma anomalia histórica, provocadora da aculturação, isto é, da perda de valores culturais e desagregação social.

A busca por uma perspectiva histórica evidenciará essas sociedades indígenas como redes de intensas relações sociais. Nesse contexto, o contato se apresenta não como anomalia, mas como áreas de trocas interculturais. São Fronteiras, áreas de fluxos, no sentido proposto por Barth (1969

Se o conceito de aculturação, necessariamente implicava na busca pelo original, não contaminado ou desestruturado pelo contato, a idéia de rede de relações sociais históricamente construídas permitiu fazer a crítica aos conceitos de autenticidade e de tradição, segundo as propostas de Hobsbawn e Ranger ( 1997 ).

Essas reflexões teóricas fizeram com que a coletora Lux Vidal não selecionasse entre a cultura material apresentada a ela pelos índios, os objetos mais "originais" e sim os considerasse como expressões materiais próprias desses grupos indígenas, portanto igualmente importantes para a coleta.

Nesse sentido, encontramos na coleção objetos que são nitidamente expressão de processos interculturais, como, por exemplo, a bolsa denominada sacole, cuja referência imediata é a sacola de design europeu, porém confeccionada com a matéria-prima, as técnicas e os grafismos do trançado próprios dos índios Karipuna. ( Foto $\mathrm{n}^{\circ} 1$ ).

A sacole é um tipo de sacola ou bolsa criada pelo artesão sr. Mário dos Santos, Karipuna da aldeia Manga. O seu referencial formal é a popular sacola, mas é feita com o uso de uma forma de madeira e com fibras de asitá ou de aru$m \tilde{a}$, segundo um trançado reto, em duas cores, de modo a se obter grafismos geométricos, pertencentes a um amplo repertório étnico, como por exemplo, as folhas da palmeira açaí ou o caminho das saúvas. ( Foto $\mathrm{n}^{\circ} 2$ ).

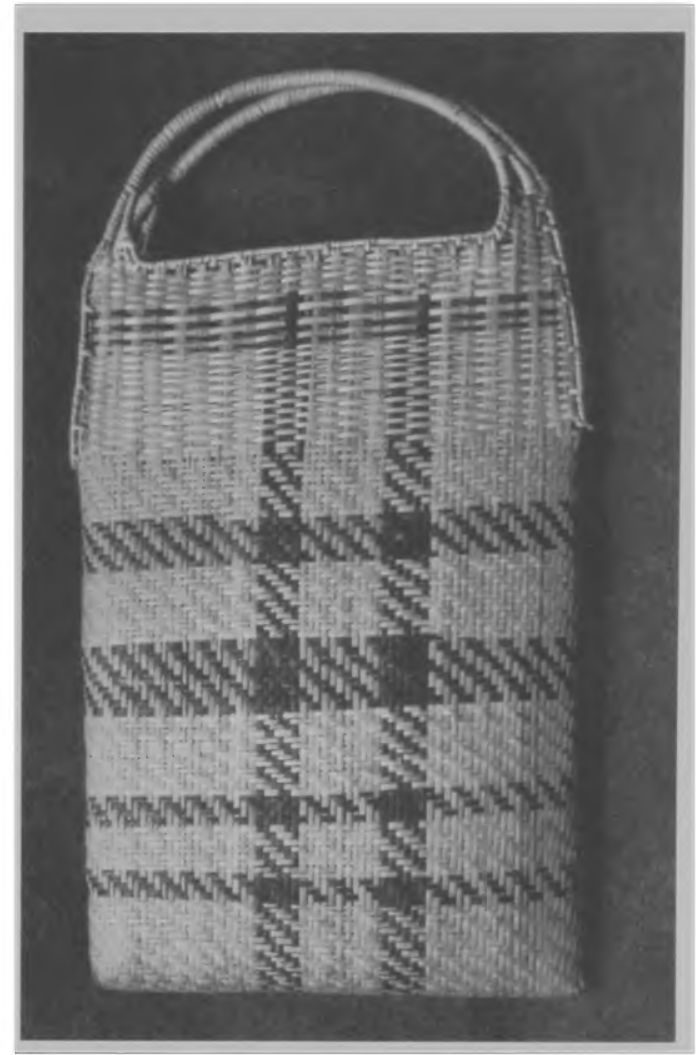

Foto $n^{o} 1$ - sacole, com o grafismo "caminho da saúva"

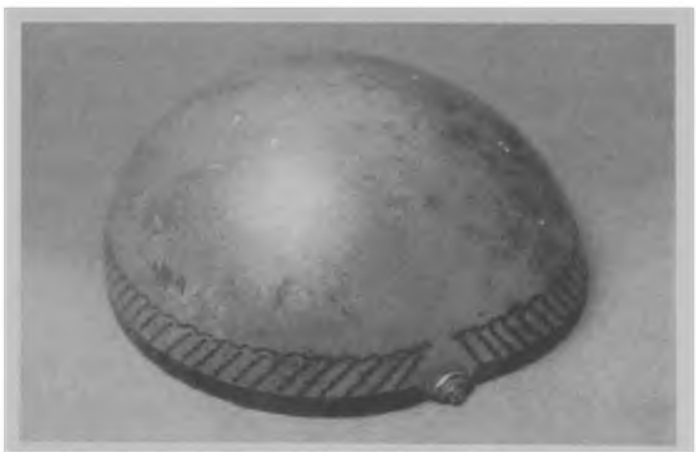

Foto $n^{\circ} 2$ - cuia, apresentando o mesmo grafismo "caminho da saúva"

\section{A Atividade Docente da Coletora}

A atividade docente de Lux Vidal vai fazer com que a coleta siga uma ordem cronológica em consonância com os grupos indígenas repre- 
sentados. À medida que as pesquisas avançam na busca pelo entendimento dos grupos indígenas e suas relações, avançam também os deslocamentos geográficos dos pesquisadores na área.

A coleção " Povos Indígenas do Oiapoque -MAE " reflete esse percurso das pesquisas. Os objetos são recolhidos em 1990 entre os Karipuna, em 1996 majoritariamente entre os Galibi Marworno, em 1997 entre os Palikur, em 1998, em grande parte entre os Galibi Marworno e no ano 2000 entre os Karipuna e Galibi Marworno.

A coletora vai a campo, desde o início das pesquisas na região, como pesquisadora- professora, encaminhando seus alunos orientandos em seus projetos específicos de pós-graduação.

Ao longo da década de 90 , podemos acompanhar seu roteiro e de seus alunos explicitado na composição da coleção, em termos de grupos indígenas representados.

Em 1990, os objetos coletados são dos indios Karipuna. Trata-se dos primeiros trabalhos de campo, em que Lux Vidal acompanha, como orientadora, Antonella M.I. Tassinari em campo. Há a inserção de ambas via os Karipuna; de um lado, porque as aldeias Karipuna, embora às margens do rio Curipi, são as mais próximas da cidade de Oiapoque, podendo ser alcançadas via ramal rodoviário e, de outro lado, porque havia um contato prévio com a família Santos,os quais constarão entre os informantes, colaboradores e amigos ao longo dos anos posteriores.

Em 1996, os objetos coletados são majoritariamente Galibi Marworno. A pesquisa avança na temática e na busca do entendimento dos outros grupos indígenas da área; espacialmente, via o rio Uaçá, a orientadora acompanha o aluno Laércio F. Dias na coleta de dados etnográficos.

Em 1997, os objetos coletados são Palikur. O espaço é mais distante, às margens do rio Urukawá. Destaca-se a coleta de Artionka Capiberibe, pois trata-se do desenvolvimento de seu trabalho de campo, na companhia da orientadora Lux Vidal.

Em 1998 temos majoritariamente objetos Galibi Marworno, entre os quais, um conjunto de 9 flechas. Trata-se da época em que a coletora acompanha os alunos zoólogos para o levantamento de aves na região.

À partir dos anos 2000 notamos na coleção a entrada de poucas categorias de objetos, destacando-se nitidamente a entrada das cuias e dos colares karipuna e Galibi Marwor- no. Essa época coincide com a formação de outra coleção, agora já com propósitos museais e voltada para a composição do acervo inicial do museu Kuahi.

\section{O Exercício da Antropologia Prática}

Se as primeiras pesquisas foram realizadas entre os Karipuna nos idos de 1990, também a participação nas primeiras Assembléias dos Povos Indígenas do Oiapoque datam desta época. Entre os projetos assessorados pela coletora Lux Vidal, destaca-se aqui o processo de construção e implantação do Museu dos Povos Indígenas do Oiapoque- Kuahi.

$\mathrm{Na}$ coleção "Povos Indígenas do Oiapoque - MAE", os objetos coletados são majoritariamente cuias e colares, não por uma escolha da coletora, mas porque foram os objetos majoritariamente apresentados pelos índios, em uma relação nitidamente de troca e também de inserção da pesquisadora na área indígena.

As redes de trocas são características dos povos indígenas da Amazônia, como tem demonstrado uma vasta bibliografia. Para a região das Guianas as redes de relações interligando povos indígenas e não indígenas são mencionadas por cronistas desde o século XVI.

Nesse viés encontramos a coletora em uma relação dialógica com os índios, em que o retorno das pesquisas desenvolvidas na área coloca-se em pauta. Por não desconsiderar qualquer objeto a coletora vai propõe um trabalho de documentação da cultura material recolhida, o que será realizado por mim, durante a década de 1990. Foi feita a documentação museográfica dos objetos, em fichas etnográficas, que contemplassem a variedade de informações etnográficas fornecidas pelos índios. O retorno dos dados catalográficos dessa coleção foi um dos elementos importantes para o desenvolvimento de reflexões sobre a memória social e a cultura material desses grupos indígenas, mostrando-se um elemento importante para a concepção de um museu indígena.

Um longo processo em curso, no qual destacamos a formação, a partir de 2000 , de uma 
coleção proposta pelos índios, com objetivos museais, a conquista do museu dos Povos Indígenas do Oiapoque - Kuahi, na cidade de Oiapoque, os cursos de capacitação museológia dos índios e a curadoria em parceria com Lux Vidal, da exposição " A Presença do invisível ", no Museu do Índio, na cidade do Rio de Janeiro.

\section{Bibliografia:}

Barbosa, G. C. " Das trocas de bens". Gallois, D. T. ( org.) Redes de relações nas Guianas São Paulo: NHII/USP?FAPESP. 2005.

Barth, F ( org). "Introduction' Ethnic Groups and Boundaries: The Social Organization of Culture Difference. London; universitets FORLAGET. 1969.

Camargo, M. Museu: Aquisição/ Documentação Técnicas apropriadas para a preservação dos bens culturais. Rio de Janeiro: Eça. 1986.
Castro, E. “ O museu dos povos indígenas do Oiapoque: um lugar de produção, conservação e divulgação da cultura". Silva, M.K.L.F. ( org. ) Práticas pedagógicas na escola indígena. São Paulo: Global/MARI/ USP/ FAPESP. 2001.

Clifford, J. A experiência etnográfica - antropologia e literatura no século XX. São Paulo: UFRJ. 1998.

Godelier, M. O enígma do Dom. Rio de Janeiro: Civilização Brasileira. 2001.

Gordon,C. \& Silva, F.A. “Objetos vivos: a curadoria da coleção etnográfica Xikrin-Kayapó no Museu de Arqueologia e Etnologia - MAE/USP"

Estudos Históricos. n. 36. Rio de Janeiro: M.N./ UFRJ. 2005.

Hobsbawn, E. \& Ranger,T. (org.). A Invenção das Tradições. Rio de Janeiro: Paz e Terra. 1997.

PEARCE, S. Interpreting Objects and Collections. London, Routledge. 1999.

Vidal, L. B. Cadernos de Campo. 1990, 1991, 1995, 1996, 1998. 